\title{
New Soil Property Database Improves Oklahoma Mesonet Soil Moisture Estimates*
}

\author{
BETHANY L. SCOTT AND TYSON E. OCHSNER \\ Plant and Soil Sciences, Oklahoma State University, Stillwater, Oklahoma \\ BRAdLEy G. ILlSTON AND CHRISTOPHER A. FIEBRICH \\ Oklahoma Climatological Survey, University of Oklahoma, Norman, Oklahoma \\ JEFFERY B. BASARA \\ School of Meteorology, and Oklahoma Climatological Survey, University of Oklahoma, Norman, Oklahoma \\ Albert J. SuTHERLAND \\ Biosystems and Agricultural Engineering, Oklahoma State University, Norman, Oklahoma
}

(Manuscript received 18 April 2013, in final form 20 June 2013)

\begin{abstract}
Soil moisture data from the Oklahoma Mesonet are widely used in research efforts spanning many disciplines within Earth sciences. These soil moisture estimates are derived by translating measurements of matric potential into volumetric water content through site- and depth-specific water retention curves. The objective of this research was to increase the accuracy of the Oklahoma Mesonet soil moisture data through improved estimates of the water retention curve parameters. A comprehensive field sampling and laboratory measurement effort was conducted that resulted in new measurements of the percent of sand, silt, and clay; bulk density; and volumetric water content at -33 and $-1500 \mathrm{kPa}$. These inputs were provided to the Rosetta pedotransfer function, and parameters for the water retention curve and hydraulic conductivity functions were obtained. The resulting soil property database, MesoSoil, includes 13 soil physical properties for 545 individual soil layers across 117 Oklahoma Mesonet sites. The root-mean-square difference (RMSD) between the resulting soil moisture estimates and those obtained by direct sampling was reduced from 0.078 to $0.053 \mathrm{~cm}^{3} \mathrm{~cm}^{-3}$ by use of the new water retention curve parameters, a $32 \%$ improvement. $\mathrm{A}>0.15 \mathrm{~cm}^{3} \mathrm{~cm}^{-3}$ high bias on the dry end was also largely eliminated by using the new parameters. Reanalysis of prior studies that used Oklahoma Mesonet soil moisture data may be warranted given these improvements. No other largescale soil moisture monitoring network has a comparable published soil property database or has undergone such comprehensive in situ validation.
\end{abstract}

\section{Introduction}

In 1994, the Oklahoma Mesonet environmental monitoring system was established as a joint project between Oklahoma State University and the University of Oklahoma. The Oklahoma Mesonet consists of over

\footnotetext{
* Supplemental information related to this paper is available at the Journals Online website: http://dx.doi.org/10.1175/JTECHD-13-00084.s1.
}

Corresponding author address: Tyson Ochsner, Plant and Soil Sciences, 368 Agricultural Hall, Stillwater, OK 74078.

E-mail: tyson.ochsner@okstate.edu
115 automated stations with at least one station in each of the state's 77 counties and covers an area of approximately $181000 \mathrm{~km}^{2}$ (Fig. 1). The average distance between nearest-neighbor stations is approximately $30 \mathrm{~km}$, which makes the network suitable for the study of mesoscale meteorological phenomena (McPherson et al. 2007). Over 20 environmental variables are monitored at each station with observations collected at 5-30-min intervals (Brock et al. 1995). Beginning in 1996, heat dissipation sensors [model 229, Campbell Scientific, Inc. (CSI), Logan, Utah] were installed to monitor soil matric potential with sensors at 5-, 25-, 60-, and 75-cm depths with readings available every $30 \mathrm{~min}$ (Illston et al. 2008). 


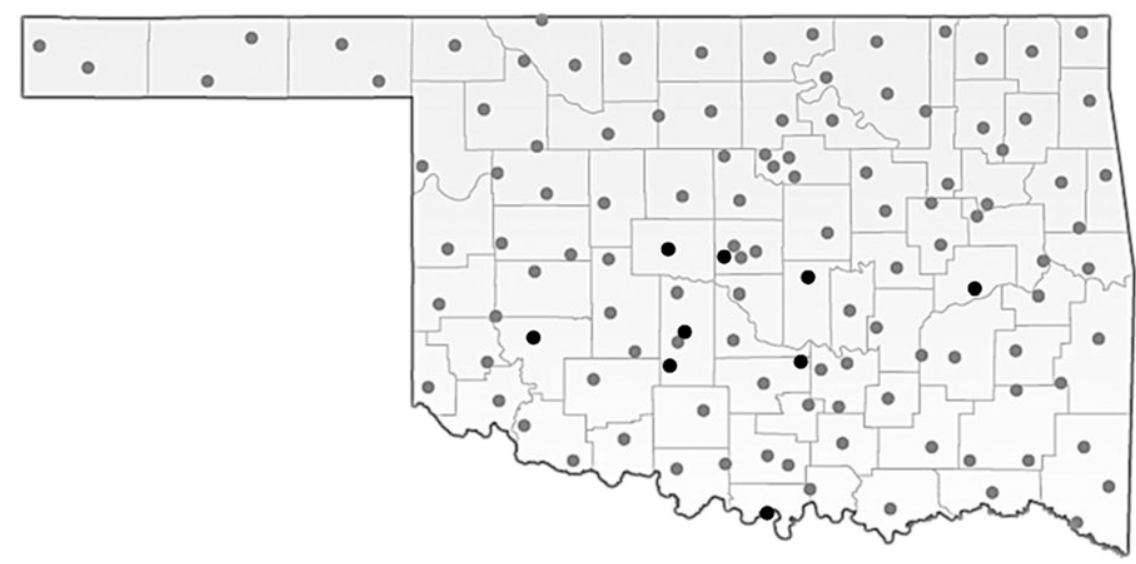

FIG. 1. Map of the Oklahoma Mesonet station locations (gray dots) with validation sites indicated (black dots).

Soil matric potential measurements from the Oklahoma Mesonet heat dissipation sensors are often converted to estimates of soil moisture (i.e., volumetric water content; e.g., Collow et al. 2012). That conversion is based on the site- and depth-specific soil water retention curve. The van Genuchten (1980) equation is used to represent the unique water retention curve for each site and depth:

$$
\frac{\theta-\theta_{r}}{\theta_{s}-\theta_{r}}=\left[1+\left(-\alpha \psi_{m}\right)^{n}\right]^{-m}
$$

The parameters include $\theta_{r}\left(\mathrm{~cm}^{3} \mathrm{~cm}^{-3}\right)$, which is the residual volumetric water content (at matric potentials $\ll 0) ; \theta_{s}\left(\mathrm{~cm}^{3} \mathrm{~cm}^{-3}\right)$, which is the saturated volumetric water content; and $\alpha, n$, and $m$, which are fitting parameters. A typical simplification followed in this study is setting $m=1-1 / n$ (Schaap et al. 2001a). Estimates of four van Genuchten parameters $\left(\theta_{r}, \theta_{s}, \alpha\right.$, and $n$ ) are thus required to calculate $\theta$ given matric potential measured by the heat dissipation sensors. Consequently, the accuracy of the Oklahoma Mesonet soil moisture data is dependent, in part, on the estimated values for the van Genuchten parameters. Previously, the van Genuchten parameters were derived using the pedotransfer function (PTF) approach developed by Arya and Paris (1981), but the accuracy of this approach is poor in some cases (Vaz et al. 2005), and newer PTFs such as Rosetta (Schaap et al. 2001a) have proven to be more accurate.

The Oklahoma Mesonet soil moisture dataset now spans more than 17 years and is one of the most widely used soil moisture datasets in the world. These data are routinely used by researchers in hydrology, meteorology, climatology, remote sensing, and related disciplines for a diverse array of studies, including research on soil moisture spatial and temporal variability (Illston et al. 2004; Lakhankar et al. 2010), land-atmosphere interactions (Godfrey and Stensrud 2008), groundwater storage estimation (Swenson et al. 2008), and soil moisture remote sensing validation (Pathe et al. 2009). Given the extent to which the Oklahoma Mesonet soil moisture data are being used, researchers need a reliable estimate for the uncertainty of these measurements and that uncertainty should be minimized as much as possible.

The primary objective of this research was to increase the accuracy of the Oklahoma Mesonet soil moisture data through improved estimates of the van Genuchten parameters for each site and depth enabled by application of the Rosetta PTF. To achieve this objective, the input data for Rosetta first had to be obtained. A preexisting soil property database contained the percent of sand, silt, and clay data for all sites and the depths with heat dissipation sensors and bulk density measurements for many, but not all, sites and depths (Illston et al. 2008). To replace this preexisting database with a new database adequate for our objective, we conducted a comprehensive field sampling and laboratory measurement effort. New measurements of sand, silt, and clay, bulk density, and $\theta$ at -33 and $-1500 \mathrm{kPa}$ were completed. These inputs were provided to Rosetta, and new parameters for Eq. (1) were obtained. We then determined the resulting reduction in the uncertainty of the Oklahoma Mesonet soil moisture data through a systemwide in situ validation. In situ validation was also completed for plant available water (PAW) values calculated using the new soil properties and soil moisture estimates because PAW is being used by the Oklahoma Mesonet as an operational agroecological drought monitoring tool (Ochsner et al. 2013). 


\section{Material and methods}

\section{a. Arya and Paris pedotransfer function}

The Arya and Paris (1981) PTF is a physical-empirical approach, in which a detailed soil particle size distribution is translated into a pore size distribution. Estimates of cumulative pore volumes corresponding to different pore radius classes are derived from the particle size distribution given knowledge of the soil bulk density. Volumetric water content is estimated for each pore radius class, and pore radii are converted to matric potential based on the capillary rise equation. In this way site- and depth-specific water retention curves were predicted for the soil layers in which the Oklahoma Mesonet heat dissipation sensors were installed. The van Genuchten parameters were then estimated by fitting Eq. (1) to the predicted water retention curves using the retention curve (RETC) program (Yates et al. 1992).

The Arya and Paris PTF does not take into account soil structure, an omission that can lead to significant errors in medium- and fine-textured soils in which the retention curve is highly influenced by soil structure (e.g. Basile and D'Urso 1997). For soils spanning a wide range of soil textural classes, comparison of $\theta$ predicted by the Arya and Paris method for a given matric potential with laboratory measured $\theta$ resulted in a rootmean-square difference (RMSD) of $0.136 \mathrm{~cm}^{3} \mathrm{~cm}^{-3}$ (Vaz et al. 2005). The method performed best for sandy soils and typically overestimated $\theta$ for fine-textured soils, especially on the dry end. The only prior direct validation of the Oklahoma Mesonet soil moisture data was conducted by sampling at 20 sites, resulting in an RMSD of $0.066 \mathrm{~cm}^{3} \mathrm{~cm}^{-3}$ between the direct $\theta$ measurements and those estimated from the heat dissipation sensors (Illston et al. 2008). We hypothesized that further reductions in the uncertainty of the Oklahoma Mesonet soil moisture data could be obtained by replacing the van Genuchten parameters derived from the Arya and Paris PTF with parameters obtained by a more advanced PTF.

\section{b. Rosetta pedotransfer function}

One of the most widely used PTFs to date is the artificial neural network (ANN) model, Rosetta (Schaap et al. 2001a). Rosetta is an ANN for estimating van Genuchten parameters, and, unlike traditional PTFs, ANNs do not require an a prior model concept. Therefore, the optimal relationship between input and output data is obtained through the calibration process (Schaap et al. 1998). Rosetta implements a hierarchical structure of five PTFs (H1-H5), which utilize an increasing numbers of input variables. The accuracy of the PTFs increases with the number of input variables. Schaap et al. (2001a) found the root-mean-square error (RMSE) between measured and estimated $\theta$ decreased from $0.078 \mathrm{~cm}^{3} \mathrm{~cm}^{-3}$ for model $\mathrm{H} 1$ with only the textural class as an input to $0.044 \mathrm{~cm}^{3} \mathrm{~cm}^{-3}$ for model $\mathrm{H} 5$. The inputs required for model $\mathrm{H} 5$ are the percent of sand, silt, and clay; the bulk density; and $\theta$ at -33 and $-1500 \mathrm{kPa}$, which correspond approximately to the field capacity and permanent wilting point of the soil. The Rosetta H5 model (hereafter simply Rosetta) takes soil structure into account through the input of measured $\theta$ at $-33 \mathrm{kPa}$. Because of its ease of use and demonstrated accuracy (Schaap et al. 2004), Rosetta was selected in this study to estimate new van Genuchten parameters using soil samples obtained from the Oklahoma Mesonet stations. Another benefit of Rosetta is that it also provides estimates of saturated hydraulic conductivity $\left(K_{s}\right)$ and the parameters required for the van Genuchten-Mualem soil hydraulic conductivity function:

$$
K\left(S_{e}\right)=K_{0} S_{e}^{L}\left\{1-\left[1-S_{e}^{n /(n-1)}\right]^{1-1 / n}\right\}^{2}
$$

where $K_{0}\left(\mathrm{~cm} \mathrm{day}^{-1}\right)$ is a fitted matching point at saturation, $L(-)$ is an empirical parameter, and $S_{e}(-)$ is the effective saturation [i.e., $S_{e}=\left(\theta-\theta_{r}\right) /\left(\theta_{s}-\theta_{r}\right)$; Schaap et al. 2001a].

\section{c. Field sampling}

Soil cores were collected April-August of 2009 and 2010 at 117 Oklahoma Mesonet stations. A hydraulic soil core sampler (model 15-SC, Giddings Machine Co., Windsor, Colorado) was used to extract two intact replicate cores within a distance of $3 \mathrm{~m}$ from the heat dissipation sensors. Cores were collected to a depth of $80 \mathrm{~cm}$ or to bedrock, whichever was shallower, using an 8.9-cm outer diameter steel tube without a liner. The inner diameter of the cutting tip on the sample tube was $7.47 \mathrm{~cm}$. The large diameter sample tube minimized core compaction during sampling. The absence of compaction was verified by measuring and comparing the length of the core and the depth of the bore hole. Care was taken to minimize sampling impacts to the stations by backfilling all bore holes with sand.

The cores were cut in the field, and only core sections consisting of the 3-10-, 20-30-, 40-50-, 55-65-, and 70$80-\mathrm{cm}$ depths were retained. The top $3-\mathrm{cm}$ section of each core was discarded because the dense near-surface root systems, which were present at many sites, prevented accurate measurements (Mohanty et al. 2002). Each core section depth interval encompasses the depth of existing heat dissipation sensors, excluding the 40$50-\mathrm{cm}$ interval, which is a candidate depth for future sensor installation. The 70-80-cm interval corresponds to 
sensors at $75 \mathrm{~cm}$, which are present at many stations. These sensors were decommissioned by the Oklahoma Mesonet in January 2011; however, archived data from those sensors remain available. Each core section was sealed in a plastic bag and placed in a cooler to minimize water loss during transport to the laboratory. Core sections were weighed and placed in a controlled temperature room at $5^{\circ} \mathrm{C}$ within $24 \mathrm{~h}$ of collection.

\section{d. Laboratory measurements}

\section{1) BULK DENSITY}

An adapted version of the core method (Grossman and Reinsch 2002) was used to determine the bulk density of the core sections. The resulting bulk density represents that of the soil matrix only. A subsample of the core section was used to determine the rock fraction, or percent of particles larger than $2 \mathrm{~mm}$, present in the larger sample. The subsample was dried at $105^{\circ} \mathrm{C}$, ground using a hammer mill and, if necessary, a mortar and pestle, and then sieved through a $2-\mathrm{mm}$ sieve. The mass of the rocks in the subsample was then determined. The ratio of that mass to the dry mass of the subsample provided an estimate of the rock fraction (RF). The rock fraction was then used in the following relationship to determine the bulk density $\rho_{b}$ of the soil matrix:

$$
\rho_{b}=\frac{m_{d}(1-\mathrm{RF})}{V-\mathrm{RF} m_{d} / \rho_{r}},
$$

where $m_{d}(\mathrm{~g})$ is the mass of the dry core section including rocks, $V\left(\mathrm{~cm}^{3}\right)$ is the volume of the core section, and $\rho_{r}$ $\left(\mathrm{g} \mathrm{cm}^{-3}\right)$ is the bulk density of the rock. A rock bulk density of $2.6 \mathrm{~g} \mathrm{~cm}^{-3}$ was used because it is the average of shale and sandstone, two of the most common rock parent materials found in Oklahoma (Johnson 2008). Four core sections had large rocks that prevented subsampling. For these samples, the entire section was used as opposed to a subsample. The section was dried, separated, and the rock fraction was determined. A total of $7.4 \%$ of the core sections contained a rock fraction of $5 \%$ or greater. This method was used, as opposed to a more rigorous method for estimating rock fraction, because of the extensive area covered by the sampling plan, as well as the destructiveness of collecting samples large enough to accurately represent the bulk density of the soil with rocks present. The bulk density data were analyzed for quality control by removing outliers from the dataset. Outliers were determined as values that were 2 times the interquartile range (IQR) below the first quartile or above the third quartile (Laurikkala et al. 2000).

\section{2) WATER CONTENT AT -33 AND $-1500 \mathrm{KPA}$}

The amount of water remaining in the soil after equilibration at $-33 \mathrm{kPa}$ was measured by the pressure cell (Tempe cell) method (Dane and Hopmans 2002). The intact core sections were trimmed to a height of $\sim 4 \mathrm{~cm}$ and sealed with wax to fill the annular gap between the $8.9-\mathrm{cm}$ diameter pressure cell ring and the $7.47-\mathrm{cm}$ diameter sample (Ahuja et al. 1985). Water retention at $-1500 \mathrm{kPa}$ was measured by pressure plate extraction using a portion of the subsample from each core section described in section 2d(1) (Dane and Hopmans 2002). One sample of an unrelated homogenized bulk soil was included with every batch of samples for pressure plate extraction in order to ensure the consistency of methods across time. All gravimetric water content values were converted to volumetric water content using the core section bulk density. The water content values at -33 and $-1500 \mathrm{kPa}$ were analyzed for quality control by removing outliers from the dataset. Outliers were determined as values that were 1.5 times the IQR below the first quartile or above the third quartile. The available water capacity, or the water held between -33 and $-1500 \mathrm{kPa}$, was calculated and if the result was negative both water retention measurements were removed from the dataset.

\section{3) PARTICle SIZE Distribution}

The percent of sand, silt, and clay was determined using the hydrometer method (Gavlak et al. 1994) for a portion of the subsample from each core section described in section $2 \mathrm{~d}(1)$. Immediately prior to the hydrometer procedure, the gravimetric water content of the soil was determined by oven drying and was used to correct the sample weight in the hydrometer calculations to an oven-dry basis. This was done because the soil absorbed some water from the air in the interval (days to months) between soil grinding and the hydrometer analysis. One sample of an unrelated homogenized bulk soil was included with every batch of samples processed in the hydrometer analysis in order to ensure the consistency of methods across time.

\section{e. Application and validation of the Rosetta PTF}

The measured percent of sand, silt, and clay, bulk density, and water contents at -33 and $-1500 \mathrm{kPa}$ were averaged for the two replicate core sections representing each Oklahoma Mesonet site and depth. These average values were provided as inputs to Rosetta, and the resulting new parameters for Eqs. (1) and (2) were recorded. Nine validation sites spanning widely varying soil textural classes were selected to determine the accuracy of the Rosetta PTF for the soils of the Oklahoma 
Mesonet stations (Fig. 1). For these nine sites, water retention was measured on the replicate core sections from all five depth intervals at pressures of $-8,-16$, $-33,-66,-125,-250,-500,-1000$, and $-1500 \mathrm{kPa}$. Below $-66 \mathrm{kPa}$, the measurements were made using disturbed samples on a pressure plate, whereas at $-66 \mathrm{kPa}$ and higher pressures the measurements were made using intact samples in Tempe cells. Equation (1) was then fitted to the water retention curves, and these fitted water retention curves were compared to those estimated using Rosetta. The validation sites were Acme, Burneyville, Byars, Chickasha, El Reno, Eufala, Hobart, Oklahoma City West, and Shawnee. The accuracy of the Rosetta water retention curves was evaluated by the RMSD between the measured $\theta$ value for each pressure and the $\theta$ estimated using the new van Genuchten parameters in Eq. (1). The bias was evaluated by the mean difference (MD) of the same. Note that RMSD is not the same as the RMSE for a linear regression between the measured and estimated values.

\section{f. In situ validation of Oklahoma Mesonet soil moisture}

The volumetric water content at the time of sampling was calculated as the product of the gravimetric water content determined by oven drying the subsample described in section $2 \mathrm{~d}(1)$ and the bulk density determined from the total core section volume and dry mass (Topp and Ferré 2002). For each Oklahoma Mesonet site and depth, the heat dissipation sensor-based estimates of $\theta$ were calculated from the daily averaged normalized temperature rise ( $\left.\Delta T_{\text {ref }}\right)$ output from the sensors on the day that site was sampled. Soil matric potential was then calculated using

$$
\psi_{m}=-c \exp \left(a \Delta T_{\mathrm{ref}}\right),
$$

where $\psi_{m}$ is the matric potential $(\mathrm{kPa}) ; \Delta T_{\text {ref }}$ is the normalized temperature rise $\left({ }^{\circ} \mathrm{C}\right)$; and $c$ and $a$ are calibration constants equal to $0.717 \mathrm{kPa}$ and $1.7880^{\circ} \mathrm{C}^{-1}$, respectively (Illston et al. 2008). The $\psi_{m}$ values were converted to $\theta$ by Eq. (1) using both the preexisting van Genuchten parameters from the Arya and Paris (1981) method and the new Rosetta-based van Genuchten parameters. Uncertainty of the sensor-based $\theta$ estimates using both approaches was evaluated by comparing those estimates with the measured $\theta$ at sampling. Uncertainty in the measured $\theta$ at sampling due to the small-scale spatial variations and the unavoidable distance $(2-3 \mathrm{~m})$ between soil cores and the in situ sensors was estimated based on the RMSD between water contents from replicate soil cores for each site and depth combination.
The Oklahoma Mesonet provides statewide daily maps of PAW based on the new Oklahoma Mesonet soil database (MesoSoil) for the purpose of operational agroecological drought monitoring. The PAW values for the $i$ th soil layer is calculated as $\mathrm{PAW}_{i}=\left(\theta_{i}-\theta_{\mathrm{wp}}\right) \Delta z_{i}$, where $\theta_{i}$ is the water content of the layer, $\theta_{\mathrm{wp}}$ is the wilting point of the layer calculated by inserting $-1500 \mathrm{kPa}$ in Eq. (1), and $\Delta z_{i}$ is the layer thickness. Sums of PAW for the 0-10-, 0-40-, and 0-80-cm depths are calculated and mapped. The uncertainty of these sensor-based PAW estimates was evaluated by comparing those estimates with the PAW values calculated using the measured $\theta$ of each layer at sampling.

\section{Results and discussion}

\section{a. Soil properties}

The resulting MesoSoil database includes 13 soil properties determined using replicated samples from 545 site and depth combinations representing 117 Oklahoma Mesonet stations. The database contains the percent of sand, silt, and clay; the bulk density; the volumetric water content at -33 and $-1500 \mathrm{kPa}$; the van Genuchten parameters of residual volumetric water content $\theta_{r}$; saturated volumetric water content $\theta_{s}\left(\mathrm{~cm}^{3} \mathrm{~cm}^{-3}\right)$, alpha $\alpha\left(\mathrm{kPa}^{-1}\right)$, and $n$ (unitless); the saturated hydraulic conductivity $K_{s}\left(\mathrm{~cm} \mathrm{day}^{-1}\right)$; as well as the matching point conductivity $K_{0}\left(\mathrm{~cm} \mathrm{day}^{-1}\right)$ and the empirical parameter $L$ (unitless). Table 1 shows the input variables for Rosetta averaged by the textural class including bulk density, percent sand, percent clay, water content at $-33 \mathrm{kPa}$, and water content at $-1500 \mathrm{kPa}$. The percent silt is found by the difference. After quality control, bulk density measurements of the soil matrix ranged from 0.92 to $1.95 \mathrm{~g} \mathrm{~cm}^{-3}$ with an average of $1.50 \mathrm{~g} \mathrm{~cm}^{-3}$. Water retention measurements at $-33 \mathrm{kPa}$ ranged from 0.06 to $0.50 \mathrm{~cm} \mathrm{~cm}^{-3}$ with a mean of 0.28 and at $-1500 \mathrm{kPa}$ from 0.01 to $0.35 \mathrm{~cm}^{3} \mathrm{~cm}^{-3}$ with a mean of 0.15 . The percent of sand varied from $2 \%$ to $88 \%$, silt varied from $0 \%$ to $74 \%$, and clay varied from $4 \%$ to $78 \%$ (Fig. 2). Of the 12 textural classes in the U.S. Department of Agriculture (USDA) classification scheme, all except sand and silt were represented. Fine textures were well represented in the database with $70 \%$ of samples having greater than $20 \%$ clay content. The clay and loam classes had the most representation at 85 samples each, whereas loamy sand and sandy clay had the least representation at 6 samples each.

Table 2 provides a textural class average hydraulic parameter lookup table for the soils of Oklahoma similar to the Rosetta H1 model (Schaap et al. 2001b). The values in Table 2 are simply the averages, for each 
TABLE 1. Number of samples in each textural class $(N)$ and textural class mean and standard deviation of bulk density $\left(\rho_{b}\right)$, percent sand, percent clay, water content at $-33 \mathrm{kPa}\left(\theta_{-33}\right)$, and water content at $-1500 \mathrm{kPa}\left(\theta_{-1500}\right)$. Abbreviated textural classes are loamy sand (L sand), sandy clay (S clay), sandy clay loam (S C L), sandy loam (S loam), silty clay loam (Si C L), silty clay (Si clay), and silt loam (Si loam).

\begin{tabular}{|c|c|c|c|c|c|c|c|c|c|c|c|}
\hline \multirow{2}{*}{$\frac{\text { Textural class }}{\text { Clay }}$} & \multirow{2}{*}{$\begin{array}{l}N \\
85\end{array}$} & \multicolumn{2}{|c|}{$\rho_{b}\left(\mathrm{~g} \mathrm{~cm}^{-3}\right)$} & \multicolumn{2}{|c|}{ Sand (\%) } & \multicolumn{2}{|c|}{ Clay (\%) } & \multicolumn{2}{|c|}{$\theta_{-33}\left(\mathrm{~cm}^{3} \mathrm{~cm}^{-3}\right)$} & \multicolumn{2}{|c|}{$\begin{array}{c}\theta_{-1500} \\
\left(\mathrm{~cm}^{3} \mathrm{~cm}^{-3}\right)\end{array}$} \\
\hline & & 1.52 & $(0.16)$ & 17.4 & (9.4) & 52.8 & (8.6) & 0.38 & $(0.06)$ & 0.25 & $(0.05)$ \\
\hline C loam & 83 & 1.51 & $(0.15)$ & 30.6 & (6.3) & 32.9 & (3.7) & 0.28 & $(0.05)$ & 0.15 & $(0.04)$ \\
\hline Loam & 85 & 1.46 & $(0.15)$ & 41.1 & (6.0) & 20.7 & (4.2) & 0.23 & $(0.05)$ & 0.09 & $(0.03)$ \\
\hline L sand & 6 & 1.49 & $(0.21)$ & 81.7 & (3.8) & 6.9 & (2.9) & 0.09 & $(0.02)$ & 0.02 & $(0.01)$ \\
\hline Sand & N/A & - & - & - & - & - & - & - & - & - & - \\
\hline S clay & 6 & 1.67 & $(0.15)$ & 53.7 & (4.6) & 40.5 & (5.8) & 0.34 & $(0.03)$ & 0.21 & $(0.03)$ \\
\hline S C L & 37 & 1.57 & $(0.19)$ & 55.7 & (7.4) & 25.8 & (4.1) & 0.22 & $(0.05)$ & 0.12 & $(0.04)$ \\
\hline S loam & 58 & 1.51 & $(0.21)$ & 66.5 & $(9.5)$ & 12.8 & (3.9) & 0.16 & $(0.05)$ & 0.06 & $(0.02)$ \\
\hline Silt & N/A & - & - & - & - & - & - & - & - & - & - \\
\hline Si C L & 56 & 1.45 & $(0.20)$ & 13.2 & (4.7) & 33.9 & (3.7) & 0.28 & $(0.05)$ & 0.10 & $(0.03)$ \\
\hline Si clay & 55 & 1.58 & $(0.13)$ & 9.9 & (4.3) & 45.3 & (3.6) & 0.38 & $(0.05)$ & 0.25 & $(0.05)$ \\
\hline Si loam & 70 & 1.48 & $(0.18)$ & 21.1 & (7.6) & 18.7 & (4.6) & 0.31 & $(0.05)$ & 0.17 & $(0.05)$ \\
\hline
\end{tabular}

textural class, of the soil hydraulic parameters estimated by applying Rosetta across all the sampled Oklahoma Mesonet sites. The Rosetta H1 class average table produced by Schaap et al. (2001b) had all textural classes represented; however, the majority of samples were coarse or medium textured. A larger percentage of the Oklahoma Mesonet station soils are fine textured, making the development of an Oklahoma-specific table beneficial. In the absence of better information, the parameters in Table 2 can be applied for interpreting soil moisture data from other monitoring networks in the region such as the U.S. Department of Energy Atmospheric Radiation Measurement Program Southern Great Plains network (Schneider et al. 2003) and the U.S. Department of Agriculture Agricultural Research Service Micronet (Steiner et al. 2008). The class average residual water contents $\theta_{r}$ and saturated water contents $\theta_{s}$ in the MesoSoil database are generally lower than the Rosetta class average values. Class average $\alpha$ and $n$ values were similar between the two datasets. The MesoSoil database values for saturated hydraulic conductivity $K_{s}$ tended to be lower for fine textures and higher for coarse textures relative to the Rosetta lookup table, with the largest difference in the loamy sand texture class. The matching point, $K_{0}$, followed the same trend as $K_{s}$ with the largest discrepancy in the loamy sand. The empirical parameter $L$ values are comparable to the Rosetta lookup table values with few exceptions. In both datasets, $L$ tended to be less than zero.

\section{b. Rosetta validation}

The Rosetta-derived van Genuchten parameters were able to reasonably predict the water retention curves measured in the laboratory for the five selected depth intervals at the nine validation sites. The water retention curves for the Burneyville site are shown in Fig. 3. All five depths intervals are sandy loam, making this the coarsest-textured validation site and one of the coarsesttextured sites in the Oklahoma Mesonet. The RMSD of the direct fit to Eq. (1) varied with depth from 0.010 to $0.025 \mathrm{~cm}^{3} \mathrm{~cm}^{-3}$. This much uncertainty is attributable to model error in Eq. (1) and laboratory measurement errors. The RMSD of the curves based on the Rosetta predictions were only slightly higher, varying from 0.013 to $0.035 \mathrm{~cm}^{3} \mathrm{~cm}^{-3}$. The steplike pattern in the water retention curves between -66 and $-125 \mathrm{kPa}$, most notable in the data from the 20- to 30-cm depth layer, may be related to the fact that for pressures below $-66 \mathrm{kPa}$ the measurements were made using disturbed samples on a pressure plate, whereas at $-66 \mathrm{kPa}$ and higher pressures the measurements were made using intact samples in Tempe cells.

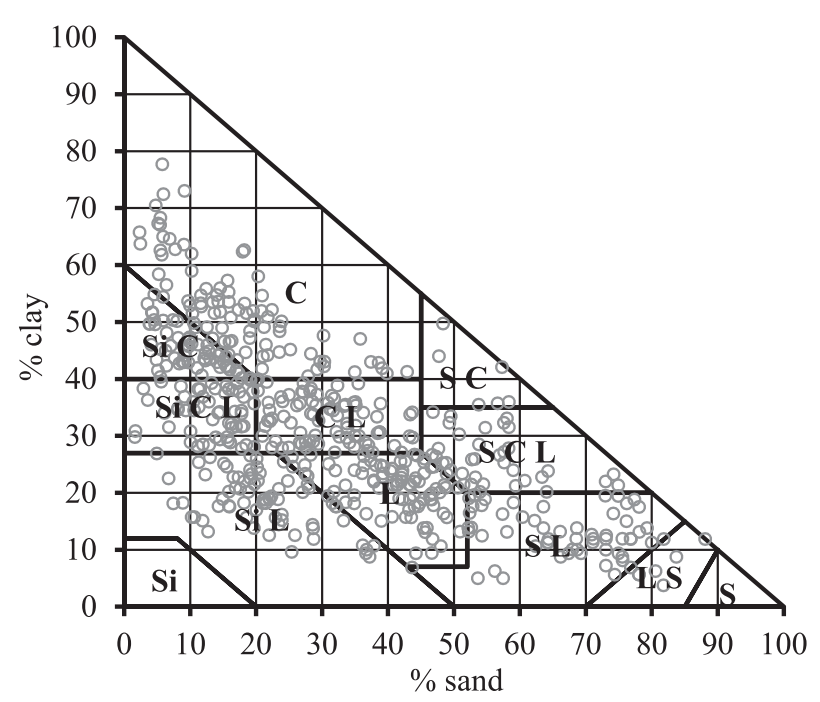

FIG. 2. Particle size distribution for the soils of the Oklahoma Mesonet stations at the sampled depths. 
TABLE 2. Textural class average hydraulic parameter lookup table for the soils of the Oklahoma Mesonet. Number of samples in each textural class $(N)$ and textural class average residual water content $\left(\theta_{r}\right)$, saturated water content $\left(\theta_{s}\right)$, fitting parameters $\alpha$ and $n$, saturated hydraulic conductivity $\left(K_{s}\right)$, fitted matching point at saturation $\left(K_{0}\right)$, and empirical parameter $(L)$. See Table 1 for textural class expansions.

\begin{tabular}{|c|c|c|c|c|c|c|c|c|c|c|c|c|c|c|c|}
\hline \multirow{2}{*}{$\frac{\text { Textural class }}{\text { Clay }}$} & \multirow{2}{*}{$\begin{array}{l}N \\
85\end{array}$} & \multicolumn{2}{|c|}{$\begin{array}{c}\theta_{r} \\
\left(\mathrm{~cm}^{3} \mathrm{~cm}^{-3}\right)\end{array}$} & \multicolumn{2}{|c|}{$\begin{array}{c}\theta_{s} \\
\left(\mathrm{~cm}^{3} \mathrm{~cm}^{-3}\right)\end{array}$} & \multicolumn{2}{|c|}{$\alpha\left(\mathrm{kPa}^{-1}\right)$} & \multicolumn{2}{|c|}{$n$ (unitless) } & \multicolumn{2}{|c|}{$K_{s}\left(\mathrm{~cm} \mathrm{day}^{-1}\right)$} & \multicolumn{2}{|c|}{$\begin{array}{c}K_{0} \\
\left(\mathrm{~cm} \mathrm{day}^{-1}\right) \\
\end{array}$} & \multicolumn{2}{|c|}{$L$ (unitless) } \\
\hline & & 0.07 & $(0.01)$ & 0.45 & $(0.04)$ & 0.13 & $(0.10)$ & 1.26 & $(0.10)$ & 11.3 & (15.2) & 3.5 & (3.2) & -1.2 & (1.5) \\
\hline C loam & 83 & 0.06 & & 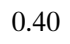 & & & & & & & & & & & $(0.7)$ \\
\hline Loam & 85 & 0.04 & $(0.01)$ & 38 & $(0.0$ & 6 & $(0.1)$ & 1.43 & & 22.7 & $(1<$ & & 1) & & $(0.6)$ \\
\hline L sand & 6 & 0.02 & $(0.01)$ & 0.38 & $(0.05)$ & 0.58 & $(0.15)$ & 1.55 & $(0.15)$ & 302.5 & (201) & 67.0 & $(48.2)$ & -1.1 & $(0.1)$ \\
\hline Sand & J/A & - & - & - & - & - & - & - & - & - & - & - & - & - & - \\
\hline S clay & 6 & 0.06 & $(0.01)$ & 0.39 & $(0.04)$ & 0.11 & $(0.11)$ & 1.28 & $(0.06)$ & 16.8 & $(33.0)$ & 3.9 & $(4.4)$ & -0.6 & (1.1) \\
\hline S C L & 37 & 0.05 & $(0.01)$ & 0.38 & $(0.04)$ & 0.29 & $(0.16)$ & 1.35 & $(0.06)$ & 60.0 & $(73.2)$ & 16.9 & (19.1) & -1.2 & $(0.6)$ \\
\hline S loam & 58 & 0.03 & $(0.01)$ & 0.37 & $(0.05)$ & 0.35 & (0.18) & 1.41 & $(0.08)$ & 101.5 & (97.6) & 26.6 & $(22.5)$ & -0.9 & $(0.6)$ \\
\hline Silt & N/A & - & - & - & - & - & - & - & - & - & - & - & - & - & - \\
\hline Si clay & 55 & 0.08 & $(0.01)$ & 0.43 & $(0.03)$ & 0.16 & $(0.11)$ & 1.25 & $(0.12)$ & 3.7 & (4.4) & 3.5 & (2.1) & -2.2 & $(2.3)$ \\
\hline Si C L & 56 & 0.07 & $(0.03)$ & 0.42 & $(0.03)$ & 0.16 & $(0.12)$ & 1.36 & $(0.13)$ & 10.3 & $(7.2)$ & 5.4 & (7.6) & -1.1 & (1.8) \\
\hline Si loam & 70 & 0.04 & $(0.02)$ & 0.39 & $(0.04)$ & 0.09 & $(0.10)$ & 1.58 & $(0.25)$ & 22.5 & (27.1) & 4.6 & (6.2) & 0.1 & (0.6) \\
\hline
\end{tabular}

The water retention curves for the Shawnee site, the finest-textured validation site, are shown in Fig. 4. The textural classes were silt loam at $3-10 \mathrm{~cm}$, silty clay loam at $20-30 \mathrm{~cm}$, and silty clay from 40 to $80 \mathrm{~cm}$. The greatest deviation from the direct fit data can be seen in the finest-textured silty clay from 40 to $80 \mathrm{~cm}$. The RMSD of the direct fit varied from 0.010 to $0.015 \mathrm{~cm}^{3} \mathrm{~cm}^{-3}$, and the Rosetta prediction RMSD varied from 0.026 in the

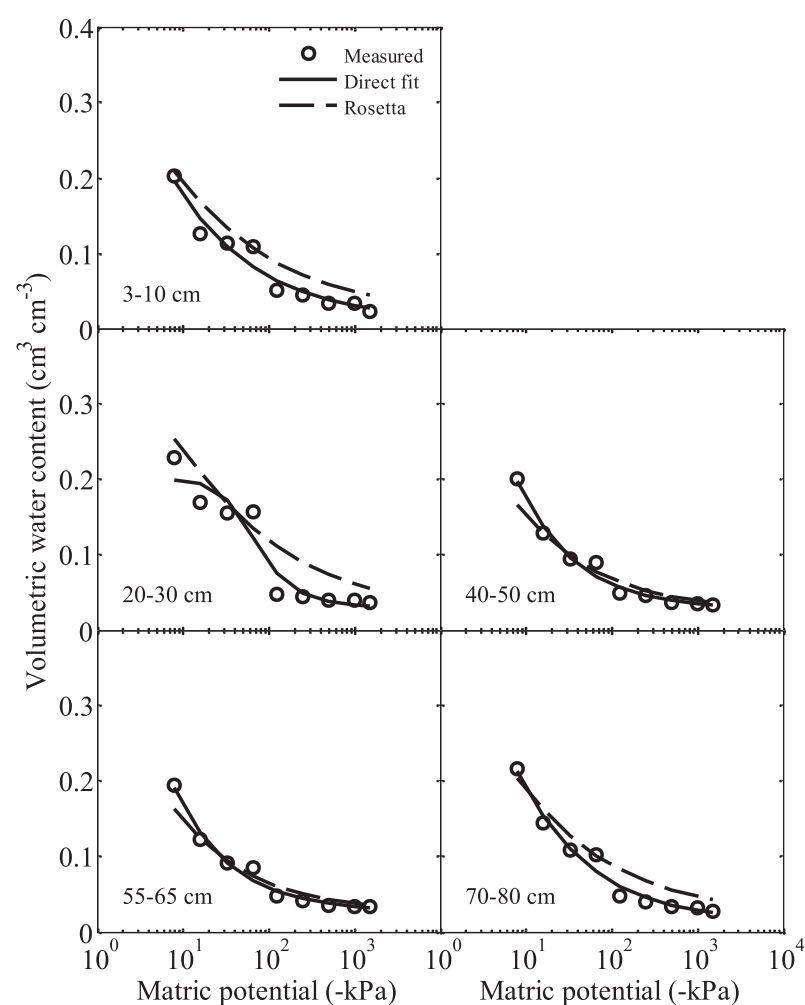

FIG. 3. Measured water retention curve (symbols), direct fit of Eq. (1) to the measured data (solid line), and water retention curve based on the parameters estimated using Rosetta (dashed line) for the Burneyville Mesonet station by sampling depth. All depths are sandy loam.

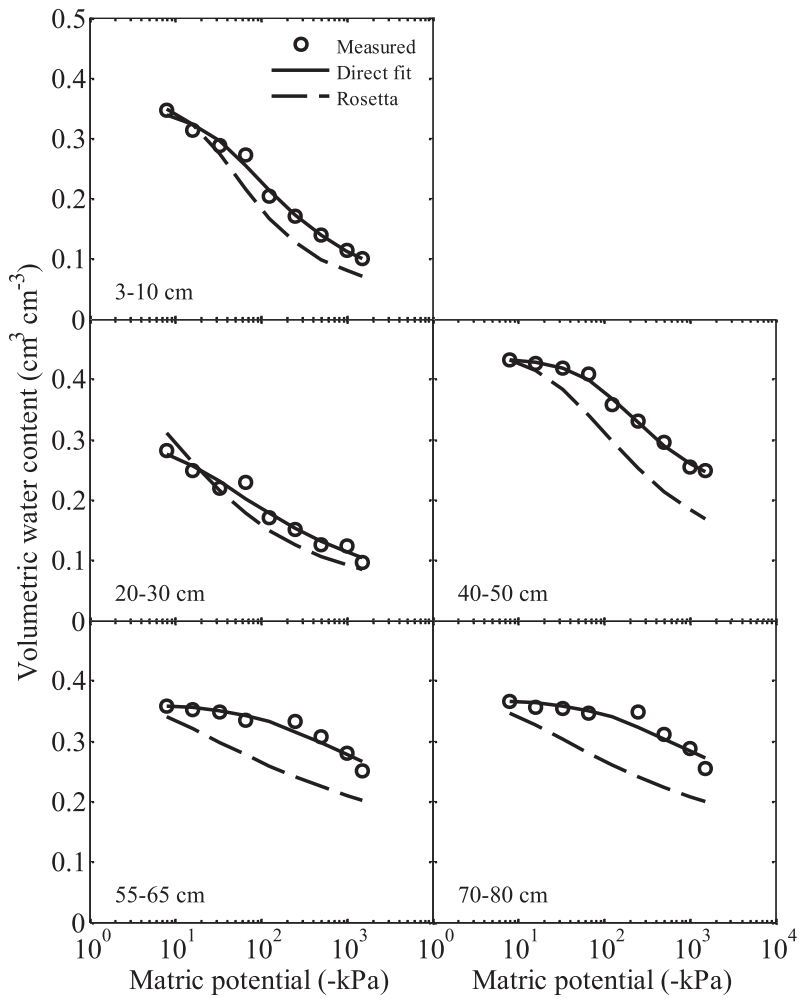

FIG. 4. Measured water retention curve (symbols), direct fit of Eq. (1) to the measured data (solid line), and water retention curve based on the parameters estimated using Rosetta (dashed line), for the Shawnee Mesonet station by sampling depth. All depths are fine textures with silt loam at 3-10 cm, silty clay loam at $20-30 \mathrm{~cm}$, and silty clay from $40-80 \mathrm{~cm}$. 


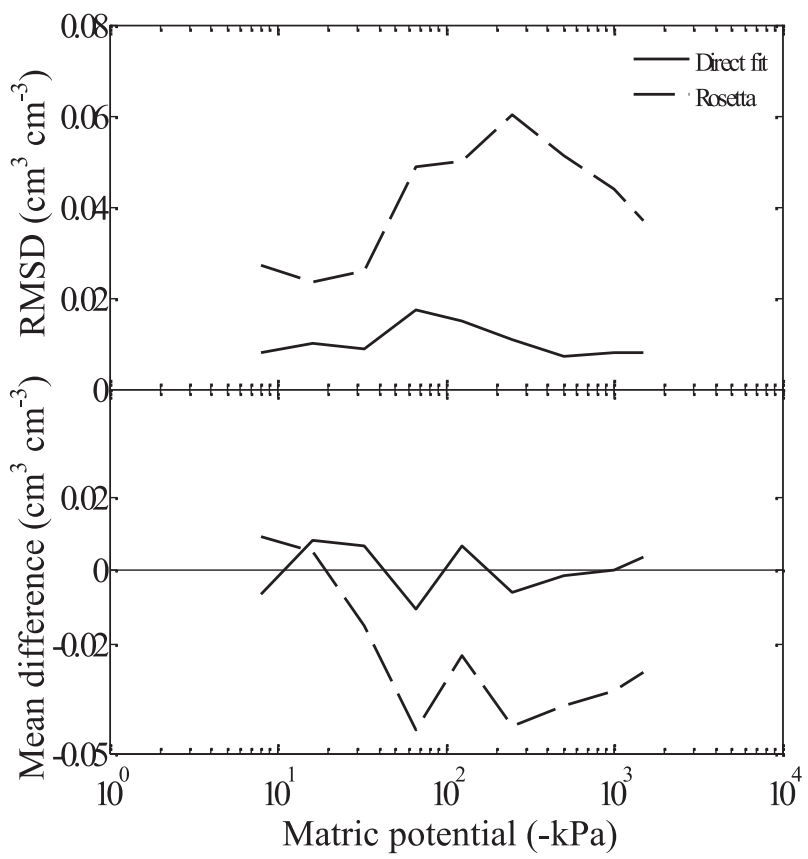

FIG. 5. RMSD and mean difference for direct fit of Eq. (1) to the measured water retention data for the validation sites (solid line) and for the water retention curves based on the parameters estimated using Rosetta (dashed line).

silty clay loam to 0.068 in the silty clay. In general, Rosetta tended to better predict the water retention curves for coarse-textured soil.

The RMSD and MD averaged across all nine validation sites for the direct fit of Eq. (1) to the measured water retention data and for the Rosetta-derived water retention curves are shown in Fig. 5. Across the measured range of matric potentials, the RMSD for the direct fit of Eq. (1) to the data averaged $0.011 \mathrm{~cm}^{3} \mathrm{~cm}^{-3}$ and remained relatively constant. The greatest RMSD of 0.017 occurred at $-66 \mathrm{kPa}$. The RMSD of the Rosetta water retention curves averaged $0.043 \mathrm{~cm}^{3} \mathrm{~cm}^{-3}$ with a minimum RMSD of $\sim 0.025$ at the lowest pressures increasing to a high of 0.060 at $-250 \mathrm{kPa}$ and decreasing to 0.037 at $-1500 \mathrm{kPa}$. The mean difference of the direct fit of Eq. (1) to the data averaged $1.2 \times 10^{-4} \mathrm{~cm}^{3} \mathrm{~cm}^{-3}$ with the greatest error of $0.007 \mathrm{~cm}^{3} \mathrm{~cm}^{-3}$ at -33 and $-125 \mathrm{kPa}$. Rosetta tended to underestimate the water content compared to the laboratory-measured water retention curve data with an average MD of $-0.023 \mathrm{~cm}^{3} \mathrm{~cm}^{-3}$. The magnitude of the MD was greatest at -66 and $-250 \mathrm{kPa}$ at $-0.043 \mathrm{~cm}^{3} \mathrm{~cm}^{-3}$. At matric potential values near zero, the MD was $\sim 0.01$ while at matric potential values from 500 to $1500 \mathrm{kPa}$ the MD was $-0.03 \mathrm{~cm}^{3} \mathrm{~cm}^{-3}$.

These validation results are similar to those reported by Schaap et al. (2001a) who found an average RMSD between measured and estimated water contents of

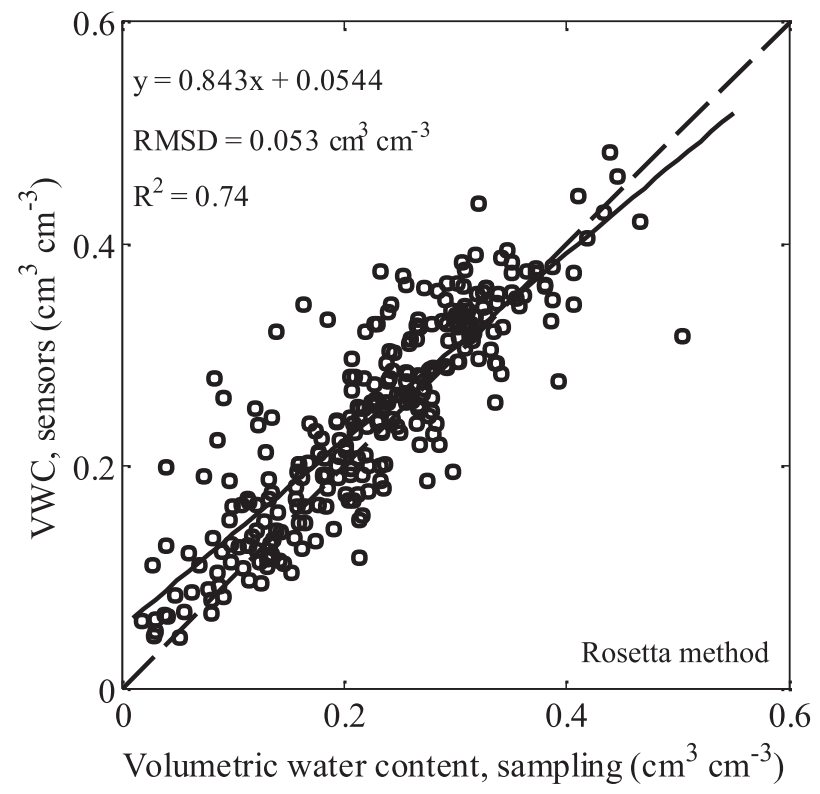

FIG. 6. Volumetric water content (VWC) calculated from the daily average $\Delta T_{\text {ref }}$ output from the Oklahoma Mesonet heat dissipation sensors on the day of soil sampling (sensors) vs VWC determined by oven drying a subsample of the core section. The $\Delta T_{\text {ref }}$ values were converted to $\psi_{m}$ by Eq. (4) and then to VWC by Eq. (1) using the parameters in the new database. The symbols are the VWC data, the solid line is the regression line, and the dashed line is the $1: 1$ line.

$0.044 \mathrm{~cm}^{3} \mathrm{~cm}^{-3}$ when using Rosetta. This study produced an average value of $0.043 \mathrm{~cm}^{3} \mathrm{~cm}^{-3}$. Schaap et al. (2001a) found that Rosetta was biased toward underestimating water retention below $-3 \mathrm{kPa}$, with the magnitude of MD increasing from around 0 at $-3 \mathrm{kPa}$ to a maximum around $-0.025 \mathrm{~cm}^{3} \mathrm{~cm}^{-3}$ at $-200 \mathrm{kPa}$. Our data also suggest a negative bias in the Rosetta predictions with the magnitude of MD reaching a maximum of a $-0.043 \mathrm{~cm}^{3} \mathrm{~cm}^{-3}$ in the same matric potential range. The larger negative bias in the present study may be a result of using a relatively finer-textured set of validation samples compared to the one used by Schaap et al. (2001a).

\section{c. In situ validation of Oklahoma Mesonet soil moisture}

A comprehensive in situ validation of Oklahoma Mesonet soil moisture estimates based on the new MesoSoil database was achieved by comparing 1) the volumetric water content calculated using the Rosetta van Genuchten parameters and the daily average $\Delta T_{\text {ref }}$ output from the heat dissipation sensors on the day of soil sampling to 2) the volumetric water content determined by oven drying a subsample of each core section collected during soil sampling (Fig. 6). The RMSD 


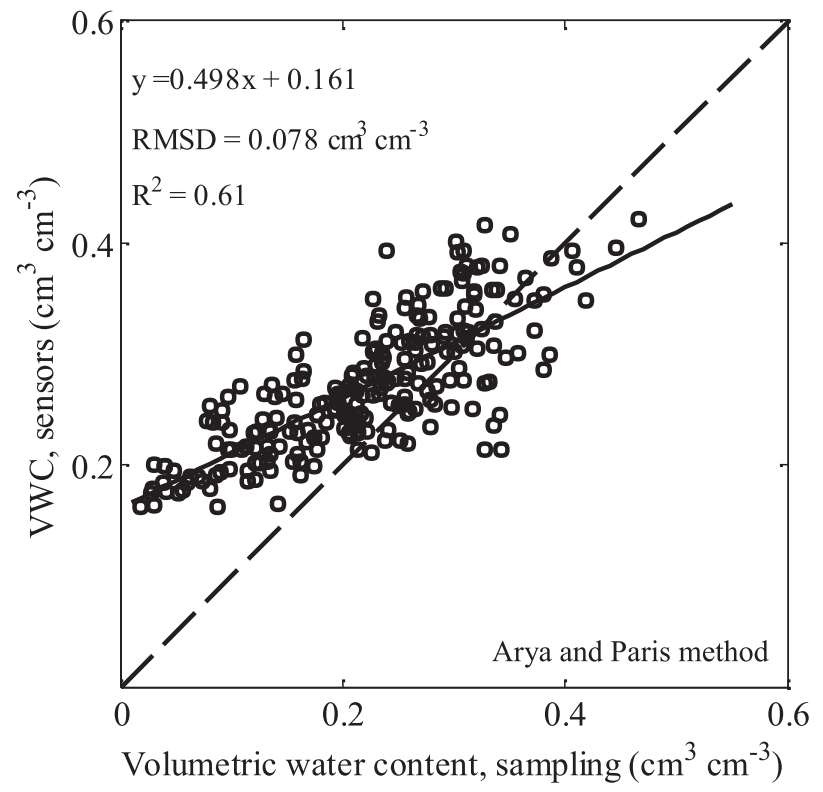

FIG. 7. VWC calculated from the daily average $\Delta T_{\text {ref }}$ output from the Oklahoma Mesonet heat dissipation sensors on the day of soil sampling (sensors) vs VWC determined by oven drying a subsample of the core section. The $\Delta T_{\text {ref }}$ values were converted to $\psi_{m}$ by Eq. (4) and then to VWC by Eq. (1) using the existing parameters found by the Arya and Paris method. The symbols are the VWC data, the solid line is the regression line, and the dashed line is the $1: 1$ line.

for this complete dataset was $0.053 \mathrm{~cm}^{3} \mathrm{~cm}^{-3}$. This is the best current estimate for the overall networkwide uncertainty of the Oklahoma Mesonet soil water content data when using the new MesoSoil database. The RMSD decreased with depth from $0.061 \mathrm{~cm}^{3} \mathrm{~cm}^{-3}$ at $5 \mathrm{~cm}$ to 0.053 at $25 \mathrm{~cm}, 0.044$ at $60 \mathrm{~cm}$, and 0.033 at $75 \mathrm{~cm}$. The slope for the regression was significantly different from one based on the $95 \%$ confidence interval, and the intercept is significantly different from zero.

The volumetric water content at sampling estimated from the preexisting Arya and Paris-derived van Genuchten parameters had substantial bias at the dry end as indicated by overestimation of the water content by $>0.15 \mathrm{~cm}^{3} \mathrm{~cm}^{-3}$ in that range (Fig. 7). The RMSD of the complete dataset was $0.078 \mathrm{~cm}^{3} \mathrm{~cm}^{-3}$ based on sampling at 117 Oklahoma Mesonet sites, which is larger than the published value of 0.066 , which was based on a smaller subset of sites (Illston et al. 2008). The RMSD decreased with depth from $0.089 \mathrm{~cm}^{3} \mathrm{~cm}^{-3}$ at $5 \mathrm{~cm}, 0.078$ at $25 \mathrm{~cm}, 0.062$ at $60 \mathrm{~cm}$, and 0.067 at $75 \mathrm{~cm}$. The slope and intercept for the regression are significantly different from one and zero, respectively, based on a $95 \%$ confidence interval. The new database led to a $32 \%$ improvement in the RMSD of volumetric water content for the Oklahoma Mesonet and a large reduction in

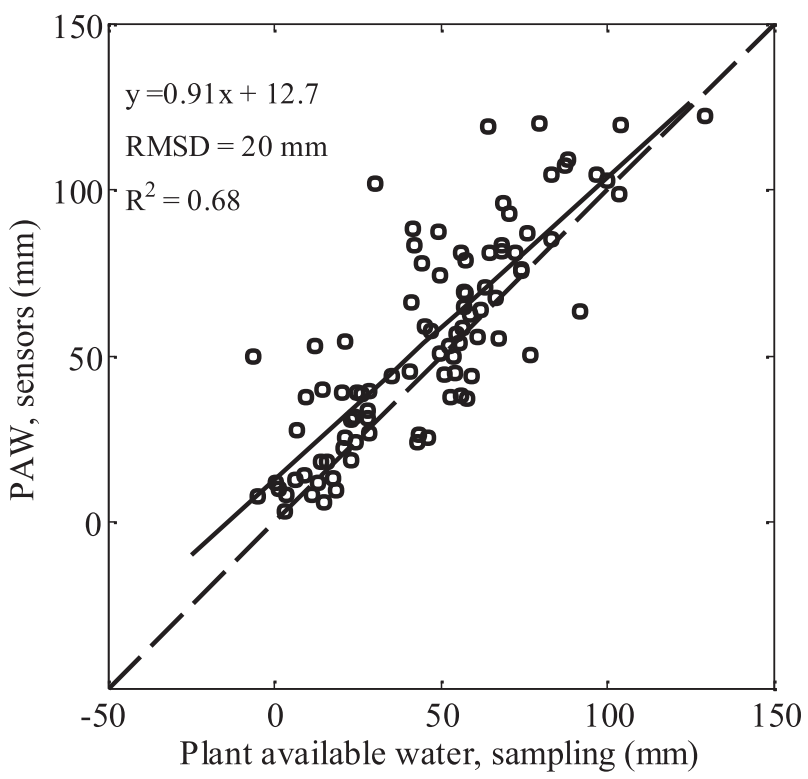

FIG. 8. PAW for $0-40 \mathrm{~cm}$ calculated through the daily average $\Delta T_{\text {ref }}$ output from the Oklahoma Mesonet heat dissipation sensors on the day of soil sampling vs plant available water determined by oven drying. The symbols are the PAW data, the solid line is the regression line, and the dashed line is the $1: 1$ line.

bias on the dry end. The uncertainty of the Oklahoma Mesonet operational 0-40-cm PAW estimates can be estimated by Fig. 8, which shows PAW from the sensors versus that determined by soil sampling. The resulting RMSD of $20 \mathrm{~mm}$ corresponds approximately to the RMSD value of $0.053 \mathrm{~cm}^{3} \mathrm{~cm}^{-3}$ from Fig. 6 multiplied by the profile thickness $(400 \mathrm{~mm})$. The $R^{2}$ value was 0.68 , and the slope was not significantly different than the one at 0.91 ; however, the intercept was significantly different from zero.

Few, if any, similar validation efforts have been attempted for other soil moisture monitoring networks of comparable size. In situ validation has not been reported for nationwide networks in the United States such as the Natural Resources Soil Conservation Service Soil Climate Analysis Network (Schaefer et al. 2007) or the National Oceanic and Atmospheric Administration Climate Reference Network (Collins 2010) nor are the authors aware of any validation studies for other statewide soil moisture networks such as those in Nebraska, Georgia, Illinois, or North Carolina. Large-scale soil moisture networks also exist outside of the United States [e.g., the Tibetan Plateau Observatory (TibetObs); Su et al. 2011] and OzNet (Smith et al. 2012), but again in situ validation has not been reported to date. Thus, the Oklahoma Mesonet appears to be the only large-scale network in the world providing soil moisture data that is both calibrated and validated in situ. 
The best available estimate for the uncertainty of the Oklahoma Mesonet soil moisture data is $\pm 0.053 \mathrm{~cm}^{3} \mathrm{~cm}^{-3}$. To identify opportunities to further reduce this uncertainty, one must consider the underlying sources of error.

Possible sources of error include 1) errors due to spatial variability at the scale of $2-3 \mathrm{~m}$, the separation distance between replicate cores and between the cores and the heat dissipation sensors; 2) sensor errors present in the $\Delta T_{\text {ref }}$ values; 3 ) errors present in the laboratory measurements; 4) errors arising from hysteresis in the water retention curves; and 5) model error in Eqs. (1) or (4) or in the Rosetta PTF. The RMSD between duplicate core sections for the water content at sampling, at $-33 \mathrm{kPa}$, and at $-1500 \mathrm{kPa}$ were $0.036,0.040$, and $0.038 \mathrm{~cm}^{3} \mathrm{~cm}^{-3}$, respectively. This means that a substantial portion of the $0.053 \mathrm{~cm}^{3} \mathrm{~cm}^{-3}$ overall uncertainty likely arises from small-scale spatial variability in $\theta$ at the Oklahoma Mesonet sites. The model error in Rosetta, approximately $0.043 \mathrm{~cm}^{3} \mathrm{~cm}^{-3}$, also appears to be a significant contributor to the overall uncertainty. Sensor errors were not estimated in this study but are likely to be relatively small because laboratory measurements are used to standardize the output of every sensor prior to installation (Illston et al. 2008). The RMSD contribution of model error in Eq. (1) is approximately $0.011 \mathrm{~cm}^{3} \mathrm{~cm}^{-3}$, the average RMSD for the direct fit of Eq. (1) to the validation site water retention curves. This again is a relatively small component of the total uncertainty. The proportions of the total uncertainty attributable to errors in the laboratory measurements, to model error in Eq. (4), and to hysteresis are currently unknown. There appears to still be some room for reducing the overall uncertainty of the Oklahoma Mesonet soil moisture data if a PTF with superior performance to Rosetta, especially in fine-textured soils, can be identified or developed.

\section{Conclusions}

The new Oklahoma Mesonet soil property database (MesoSoil) is provided in the supplemental materials with this paper. Updates to the database are likely (the latest version is available for download at http:// soilphysics.okstate.edu/data). Preliminary steps toward adding soil thermal properties and soil organic carbon data to the MesoSoil database have already been taken. Through the development of the MesoSoil database the uncertainty in the Oklahoma Mesonet soil moisture data has been reduced by $32 \%$. The RMSD between the values found through direct sampling and those found using the heat dissipation sensors with the new soil properties was $0.053 \mathrm{~cm}^{3} \mathrm{~cm}^{-3}$, while the corresponding value with the preexisting soil database was $0.078 \mathrm{~cm}^{3} \mathrm{~cm}^{-3}$. The preexisting soil database resulted in overestimates of soil moisture by $>0.15 \mathrm{~cm}^{3} \mathrm{~cm}^{-3}$ on the dry end, and this bias was greatly reduced using the MesoSoil database. As such, reanalysis may be warranted for previous studies that used Oklahoma Mesonet soil moisture data. As more effective pedotransfer functions are developed, the MesoSoil database can provide input parameters that may allow for further reductions in the uncertainty of Oklahoma Mesonet soil moisture data.

The results of this study strengthen the unique position of the Oklahoma Mesonet as an invaluable research tool. It is the only large-scale soil moisture monitoring network for which comprehensive in situ validation has been reported. This makes the Oklahoma Mesonet a powerful large-scale test bed for the calibration and validation of soil moisture remote sensing platforms like the Advanced Scatterometer (ASCAT; Wagner et al. 2013), Soil Moisture and Ocean Salinity (SMOS; Kerr et al. 2010), and Soil Moisture Active Passive (SMAP; Entekhabi et al. 2010) for hydrological, ecological, and meteorological theories and models and for advanced data assimilation frameworks. Researchers using Oklahoma Mesonet soil moisture data should keep in mind that all the sites are dominated by perennial warm season vegetation and that no sites are under cropland or forest. A clear research need is to better understand how differences in land cover and land use between permanent monitoring stations and the surrounding landscape affect the uses of in situ soil moisture measurements.

Acknowledgments. Financial support for this work was provided in part by the Oklahoma Water Resources Research Institute, the Oklahoma Water Resources Board, and the Oklahoma Agricultural Experiment Station. Continued funding for the Oklahoma Mesonet network is provided by the taxpayers of the State of Oklahoma. The vital field and laboratory work of undergraduate research assistants Sam Wallace and Thomas Hyde is gratefully acknowledged.

\section{REFERENCES}

Ahuja, L. R., J. W. Naney, and R. D. Williams, 1985: Estimating soil water characteristics from simpler properties or limited data. Soil Sci. Soc. Amer. J., 49, 1100-1105.

Arya, L. M., and J. F. Paris, 1981: A physicoempirical model to predict the soil-moisture characteristic from particle-size distribution and bulk-density data. Soil Sci. Soc. Amer. J., 45, 1023-1030.

Basile, A., and G. D’Urso, 1997: Experimental corrections of simplified methods for predicting water retention curves in clay-loamy soils from particle-size determination. Soil Technol., 10, 261-272. 
Brock, F. V., K. C. Crawford, R. L. Elliott, G. W. Cuperus, S. J. Stadler, H. L. Johnson, and M. D. Eilts, 1995: The Oklahoma Mesonet: A technical overview. J. Atmos. Oceanic Technol., 12, 5-19.

Collins, W. G., 2010: The characteristics and preliminary quality control of soil moisture and temperature observations at US climate reference network sites. Preprints, 15th Symp. on Meteorological Observation and Instrumentation, Atlanta, GA, Amer. Meteor. Soc., 1.2. [Available online at https://ams. confex.com/ams/90annual/techprogram/paper_157860.htm.]

Collow, T. W., A. Robock, J. B. Basara, and B. G. Illston, 2012: Evaluation of SMOS retrievals of soil moisture over the central United States with currently available in situ observations. J. Geophys. Res., 117, D09113, doi:10.1029/2011jd017095.

Dane, J. H., and J. W. Hopmans, 2002: Water retention and storage. Methods of Soil Analysis: Physical Methods, J. H. Dane and G. C. Topp, Eds., Science Society of America Book Series, Vol. 5, Soil Science Society of America, Inc., 671-690.

Entekhabi, D., and Coauthors, 2010: The Soil Moisture Active Passive (SMAP) mission. Proc. IEEE, 98, 704-716.

Gavlak, R., D. Horneck, R. O. Miller, and J. Kotuby-Amacher, 2003: Soil, plant and water reference methods for the western region. 2nd ed. Rep. WREP-125, Wetlands Reserve Enhancement Program, Fort Collins, CO, 199 pp.

Godfrey, C. M., and D. J. Stensrud, 2008: Soil temperature and moisture errors in operational Eta model analyses. J. Hydrometeor., 9, 367-387.

Grossman, R. B., and T. G. Reinsch, 2002: Bulk density and linear extensibility. Methods of Soil Analysis: Physical Methods, J. H. Dane and G. C. Topp, Eds., Science Society of America Book Series, Vol. 5, Soil Science Society of America, Inc., 205-210.

Illston, B. G., J. B. Basara, and K. C. Crawford, 2004: Seasonal to interannual variations of soil moisture measured in Oklahoma. Int. J. Climatol., 24, 1883-1896.

,,-- D. K. Fisher, R. Elliot, C. A. Fiebrich, K. C. Crawford, K. Humes, and E. Hunt, 2008: Mesoscale monitoring of soil moisture across a statewide network. J. Atmos. Oceanic Technol., 25, 167-182.

Johnson, K. S., 2008: Geologic history of Oklahoma. Oklahoma Geological Survey Educational Publication 9, 2-9. [Available online at http://www.ogs.ou.edu/pubsscanned/EP9_2-8geol. pdf.]

Kerr, Y. H., and Coauthors, 2010: The SMOS mission: New tool for monitoring key elements of the global water cycle. Proc. IEEE, 98, 666-687.

Lakhankar, T., A. S. Jones, C. L. Combs, M. Sengupta, T. H. Vonder Haar, and R. Khanbilvardi, 2010: Analysis of large scale spatial variability of soil moisture using a geostatistical method. Sensors, 10, 913-932.

Laurikkala, J., M. Juhola, and E. Kentala, 2000: Informal identification of outliers in medical data. Fifth Int. Workshop on Intelligent Data Analysis in Medicine and Pharmacology: A workshop at the 14th European Conf. on Artificial Intelligence, Berlin, Germany, European Conference on Artificial Intelligence, 20-24.

McPherson, R. A., and Coauthors, 2007: Statewide monitoring of the mesoscale environment: A technical update on the Oklahoma Mesonet. J. Atmos. Oceanic Technol., 24, 301-321.

Mohanty, B. P., P. J. Shouse, D. A. Miller, and M. T. van Genuchten, 2002: Soil property database: Southern Great Plains 1997 hydrology experiment. Water Resour. Res., 38 (5), doi:10.1029/ 2000WR000076.
Ochsner, T. E., and Coauthors, 2013: State of the art in large-scale soil moisture monitoring. Soil Sci. Soc. Amer. J., in press.

Pathe, C., W. Wagner, D. Sabel, M. Doubkova, and J. B. Basara, 2009: Using ENVISAT ASAR global mode data for surface soil moisture retrieval over Oklahoma, USA. IEEE Trans. Geosci. Remote Sens., 47, 468-480.

Schaap, M. G., F. J. Leij, and M. T. van Genuchten, 1998: Neural network analysis for hierarchical prediction of soil hydraulic properties. Soil Sci. Soc. Amer. J., 62, 847-855.

$\longrightarrow, \ldots$, and $\longrightarrow, 2001 \mathrm{a}$ : Rosetta: A computer program for estimating soil hydraulic parameters with hierarchical pedotransfer functions. J. Hydrol., 251, 163-176.

,$- \ldots$, and - , cited 2001b: Rosetta class average hydraulic parameters. Agricultural Research Service. [Available online at http://ars.usda.gov/Services/docs.htm?docid=8955.]

- A. Nemes, and M. T. van Genuchten, 2004: Comparison of models for indirect estimation of water retention and available water in surface soils. Vadose Zone J., 3, 1455-1463.

Schaefer, G. L., M. H. Cosh, and T. J. Jackson, 2007: The USDA Natural Resources Conservation Service Soil Climate Analysis Network (SCAN). J. Atmos. Oceanic Technol., 24, 20732077, doi:10.1175/2007jtecha930.1.

Schneider, J. M., D. K. Fisher, R. L. Elliot, G. O. Brown, and C. P. Bahrmann, 2003: Spatiotemporal variations in soil water: First results from the ARM SGP CART network. J. Hydrometeor., 4, 106-120.

Smith, A., and Coauthors, 2012: The Murrumbidgee soil moisture monitoring network data set. Water Resour. Res., 48, W07701, doi:10.1029/2012WR011976.

Steiner, J., P. Starks, J. Daniel, J. Garbrecht, D. Moriasi, S. McIntyre, and J.-S. Chen, 2008: Environmental effects of agricultural conservation: A framework for research in two watersheds in Oklahoma's upper Washita River basin. J. Soil Water Conserv., 63, 443-452.

Su, Z., J. Wen, L. Dente, R. van der Velde, L. Wang, Y. Ma, K. Yang, and Z. Hu, 2011: The Tibetan Plateau Observatory of plateau scale soil moisture and soil temperature (Tibet-Obs) for quantifying uncertainties in coarse resolution satellite and model products. Hydrol. Earth Syst. Sci., 15, 2303-2316.

Swenson, S., J. Famiglietti, J. Basara, and J. Wahr, 2008: Estimating profile soil moisture and groundwater variations using GRACE and Oklahoma Mesonet soil moisture data. Water Resour. Res., 44, W01413, doi:10.1029/2007WR006057.

Topp, G. C., and P. A. Ferré, 2002: Thermogravimetric method using convection oven-drying. Methods of Soil Analysis: Physical Methods, J. H. Dane and G. C. Topp, Eds., Science Society of America Book Series, Vol. 5, Soil Science Society of America, Inc., 419.

van Genuchten, M. T., 1980: A closed-form equation for predicting the hydraulic conductivity of unsaturated soils. Soil Sci. Soc. Amer. J., 44, 892-898.

Vaz, C. M. P., M. de Freitas Iossi, J. de Mendonça Naime, Á. Macedo, J. M. Reichert, D. J. Reinert, and M. Cooper, 2005: Validation of the Arya and Paris water retention model for Brazilian soils. Soil Sci. Soc. Amer. J., 69, 577-583.

Wagner, W., and Coauthors, 2013: The ASCAT soil moisture product: A review of its specifications, validation results, and emerging applications. Meteor. Z., 22, 5-33, doi:10.1127/ 0941-2948/2013/0399.

Yates, S., M. T. van Genuchten, F. Leij, and A. Warrick, 1992: Analysis of measured, predicted, and estimated hydraulic conductivity using the RETC computer program. Soil Sci. Soc. Amer. J., 56, 347-354. 